\title{
Attentats: quand la terreur produit du sacré
}

\author{
Thomas Clavel \\ Professeur certifié de Lettres Modernes, Seine-Saint Denis
}

\section{Résumé}

A partir des réflexions de René Girard et de Philippe Muray sur le terrorisme, ce texte introduit l'hypothèse suivant laquelle la re-sacralisation de l'ère hyperfestive serait l'effet inévitable et noncalculé des attentats djihadistes en Europe. Ces postulats visent à apporter un éclairage neuf quant à la rhétorique des évènements commémoratifs et des discours médiatiques en Occident.

\section{Mots-Clefs}

Islamisme; djihadisme; attentat-suicide; sacrifice; théorie mimétique; hyperfestivisme; René Girard; Philippe Muray.

Ne se faire aucune illusion, ni sur la cible (nous, les Occidentaux), ni sur les attaquants (les islamistes), et affirmer que l'altérité (les attaquants) ne restera pas éternellement radicale, qu'elle ne l'est déjà plus, me paraissait la moindre des choses. C'est ce qui a été peu, ou mal, compris. ${ }^{1}$

\section{Philippe Muray}

\section{Introduction}

En novembre 2001, René Girard affirmait: «Le terrorisme est suscité par un désir exacerbé de convergence et de ressemblance avec l'Occident. ${ }^{2}{ }_{\gg}$ Loin d'alimenter le cliché constamment rebattu depuis - d'un islamisme guerrier supposé imperméable à notre modèle de société contemporain, l'anthropologue préférait penser la relation entre Djihad et Occident en termes de " concurrence » plutôt qu'en termes de «différence». ${ }^{3}$ Ayant fait

\footnotetext{
1 Philippe Muray, Essais (Paris : Les Belles Lettres, 2015), 1688.

2 René Girard, «Entretien », Le Monde (5 Novembre 2011),

http:/ / www.lemonde.fr/archives/article/2001/11/05/rene-girard-philosophe-et-anthropologue-cequi-se-joue-aujourd-hui-est-une-rivalite-mimetique-a-l-echelleplanetaire_239636_1819218.html?xtmc=rene_girard_tincq\&xtcr=3 (Consulté le 25 Août 2017).

3 Ibid. Dans un entretien accordé au journal La Croix, Girard décrit Oussama ben Laden comme un «homme moderne, influencé par les valeurs occidentales». Voir René Girard, "Que Valent nos

This is an Open Access article distributed in accordance with the Creative Commons Attribution Non Commercial (CC-BY-NC-ND 4.0) license, which permits others to copy or share the article, provided original work is properly cited and that this is not done for commercial purposes. Users may not remix, transform, or build upon the material and may not distribute the modified material (bttp:/ / creativecommons.org/ licenses/by-nc/4.0/)
} 
germer leur idéologie de combat sur notre propre terreau civilisationnel, nourris par le ressentiment, travaillés par des forces complémentaires d'attirance et de répulsion, nos ennemis nous ressemblent plus que nous le pensons, s'inscrivant avec nous dans un processus de rivalité mimétique. Fascinés par ce que les occidentaux désirent, ils souhaitent donc les en priver - la destruction étant, comme l'enseigne Sade, le plus haut niveau auquel la possession s'accomplit. Au fond, l'islamisme guerrier ne serait que la réaction mimétique de l'islam, sa déviance la plus contemporaine.

Mais si les terroristes cherchent à détruire ce que les occidentaux désirent, la dialectique rivalitaire s'opère naturellement en sens inverse : les occidentaux en viennent à désirer ce que les terroristes détruisent. En effet, le sujet européen se met à priser plus puissamment encore l'objet dont l'ennemi sanguinaire veut le déposséder jusqu'à en mourir. Il revendique tout ce que le kamikaze a rendu sacré par son propre sacrifice et par celui de victimes innocentes: tout à coup, un concert Pop devient porteur d'un sens supérieur; une bière en terrasse un acte de haute résistance; le feu d'artifices du 14 juillet se teinte de couleurs plus profondes; un journal hebdomadaire satirique en passe de tomber dans les oubliettes de l'Histoire ressuscite au point de se muer en bréviaire de toute une génération.

En somme, si l'islamisme guerrier produit de la violence, la violence produite génère elle aussi du religieux, réciproquement. Par le sang versé, les attentats ont ainsi sanctifié des caricatures dérisoires que les passants ne considéraient même plus, célébré les terrasses de café les plus banales, anobli les chanteuses les plus insignifiantes, fait entrer dans la lumière les groupes de musique les plus obscurs - produisant entre les consommateurs une subite solidarité factice, un simulacre de communion. Par une pirouette diabolique, ils sont devenus les impitoyables alliés de la société du spectacle, consacrant le vivre-ensemble et le festivisme ${ }^{4}$ tels des dogmes supérieurs, dont les hashtag et les Je Suis sont autant de psaumes incontournables.

Aussi, plusieurs expressions, partagées par toutes les personnes interrogées par les médias de masse à l'occasion d'un témoignage ou d'une commémoration, font désormais office de lieux communs. Mieux encore: elles constituent le Credo de cette nouvelle mystique post-attentats. Elles sont les hallucinations nécessaires à la grand-messe médiatique.

\section{« Ils ne nous changeront pas »}

C'est la réponse au désir mimétique du djihadisme. Ce qui a été attaqué est rendu sacré par l'attaque même. Loin de changer notre mode de vie, les attentats le renforcent en lui

Valeurs?", La Croix (13 Décembre 2002), http://www.la-croix.com/Archives/2002-12-13/Quevalent-nos-valeurs-Interview-Rene-Girard-_NP_-2002-12-13-171969 (Consulté le 25 Août 2017). On trouvera d'autres remarques sur la rivalité mimétique entre Djihad et Occident dans René Girard, Achever Clausewitz (Paris: Flammarion, 2011), 90 ; 354.

${ }^{4} \mathrm{Il}$ convient ici de rappeler que l'Hyperfestif ne se réduit pas à une simple multiplication des fêtes (même si elle en constitue l'un des symptômes). Il s'agit, selon Philippe Muray, d'une transformation anthropologique inédite emportant avec elle les différences essentielles (animalité/humanité, privé/public, masculin/féminin etc.) qui, jusqu'alors, faisaient l'Histoire. Pour Muray, l'Hyperfestif est indissociable de la Post-Histoire dont Homo festivus est l'habitant heureux. Voir notamment Philippe Muray, Le Portatif (Paris : Editions Mille et Une Nuits, 2006), 42-50. 
conférant un supplément d'âme artificiel. La célébration de notre mode de vie est désormais une injonction morale. La communauté se met à construire un imaginaire religieux autour de toutes les virtualités de la fête. En cela, le terrorisme entérine la victoire totale du culte festiviste: il en est son ciment le plus providentiel ${ }^{5}$.

\section{« Nous resterons unis »}

C'est le cœur nucléaire de la grand-messe compassionnelle, l'illusion nécessaire du culte victimaire. Nous ne sommes pas unis - mais nous le resterons; nous nous détestons en tant que nation - mais nous ne cesserons de nous aimer en tant que cour de récréation : tel est le grand simulacre produit par les crimes de masse. À l'heure du délitement des peuples, divisés en tout, le djihadisme agit comme la ruse de la raison de la religion multiculturelle en construisant une parodie d'union sacrée. Plus la victime est coupable aux yeux du djihadiste (à cause de son mode de vie contraire à la Charia), plus elle est innocente aux nôtres - et ce scandale participe à l'édification d'une mystique unitaire qui fonctionne comme une divine surprise à l'âge de la haine de soi et de la grande culpabilité européenne, en redonnant foi en l'Homme occidental et en ses valeurs de fête et d'amour universel.

\section{« Ça n'a rien à voir avec la religion »}

Dernièrement, s'inscrivant dans une longue tradition de pudeur sémantique, et refusant luiaussi de sombrer dans l'amalgame, Christophe Castaner, au micro d'Europe 1, disait préférer le mot d'assassins à celui de terroristes islamistes car ceux-ci n'auraient rien à voir avec la religion qu'ils trahissent. Cette passion pour la cécité qui caractérise l'homme contemporain révèle toujours une vérité structurelle: ici, dans sa concurrence mimétique avec l'ennemi occidental, le djihadiste ne saurait avoir le monopole du religieux ${ }^{6}$. Mieux encore, il s'agit de l'exclure de la sphère du sacré. Comment? En cherchant à le vider de tout contenu dogmatique - tout en invoquant par ailleurs tel Islam idéalisé, supposé pure religion de paix et d'amour. Qu'importe la véracité théologique: l'important n'est pas de connaitre l'Islamisme guerrier mais de l'aseptiser. Au fond: de le dissoudre rapidement afin de réserver

\footnotetext{
${ }^{5}$ Dans son essai Chers Djihadistes..., Muray emprunte ironiquement la voix d'Homo Festivus pour s'adresser aux terroristes. Il écrit notamment : "Nous autres Occidentaux peinions déjà depuis un certain temps à placer la fête, où se matérialise sous des espèces jubilatoires l'ordre hégémonique que nous entendons imposer (...) sous le sceau du sacré. Les désastres que vous [les djihadistes] avez provoqués le permettent enfin. » Voir Philippe Muray, Chers Djihadistes... (Paris : Editions Mille et Une Nuits, 2002), 52-53. Tout comme Girard, Muray pense la relation entre Djihad et Occident de manière mimétique : «Votre [les djihadistes] violence, même de plus en plus folle et meurtrière, ne cessera de nous renforcer en vous liant dialectiquement, et chaque fois de manière plus étroite, à nous. » Ibid., 20. Plus loin Muray écrit : «Et si vous [les djihadistes] tenez à demeurer à la hauteur de la situation sans précédent que vous avez créée, il va falloir nous imiter. » Ibid., 21.

${ }^{6}$ Cette disqualification de la dimension religieuse fait aussi l'objet de l'ironie de Muray: «Vos [les djihadistes] raisons religieuses, que nous ne pouvons prendre en compte, sauf à vous prêter justement des raisons, ce qui reviendrait à vous attribuer aussi une humanité, se perdront dans la pagaille du parc d'attractions dont nous sommes les créateurs et qui, peu à peu, supplante le reste. » Ibid., 20. Pour Muray, il ne s'agit pas seulement d'une déshumanisation de l'ennemi. La négation de la dimension religieuse du djihadisme permet à l'Occident de dénier son propre nihilisme en le rejetant sur le dos du terroriste. Voir ibid., 108-109.
} 
au seul moment compassionnel des bougies et des nounours la totalité du champ du religieux.

\section{«Ce sont des lâches »}

L'attentat-suicide cherche à mettre en concurrence deux martyrologies : l'une islamiste et guerrière, l'autre occidentale et victimaire. Dans l'imagerie médiatique, la première doit être immédiatement disqualifiée pour que la seconde soit sacralisée. Les kamikazes sont ainsi privés de leur sacrifice - en étant presque toujours réduits à l'état de démence - afin de garantir l'exclusivité du champ du sacré aux victimes innocentes dont on cherche à colorer le martyre d'un vague christianisme parodique. Car contrairement à l'histoire chrétienne dans laquelle les Saints entrent librement dans leur passion, les badauds tombés au champ de fête sont d'une bouleversante nullité religieuse. Il s'agit donc de leur conférer une mission posthume en consacrant la scène qui les a vus mourir et en reprenant leur flambeau fictif : nous sommes terrasses, aéroports, Nous Sommes Paris, Nice, Manchester ou Londres.

Par ailleurs, il n'est pas rare que les médias produisent quelque héros de circonstances tel ou tel jeune homme, si possible d'origine étrangère, ayant réalisé un garrot ou filmé l'attaque sans trembler. Bientôt, d'autres braves entreront eux aussi dans la lumière en se rendant à des concerts mémoriels, armés d'une pancarte, d'un lumignon ou d'une canette solidaire de bière, rejoignant la gigantesque surboum compassionnelle comme on prend le maquis.

\section{«Ils n'auront pas notre haine»}

Les terroristes ne sont jamais perçus comme des ennemis dignes de haine puisque le seul ennemi des nations occidentales - leur terreur sacrée - c'est leur propre division. Partant, le djihadiste intervient bien au contraire tel un allié providentiel. Comme la foudre met un terme aux tensions, l'attentat apaise la violence collective d'un peuple qui ne s'aime plus mais se rassemble grâce au sacrifice qui l'a frappé. Les petites victimes sont alors divinisées par des bougies mais sans jamais faire courir à la société le risque d'une guerre civile par un appel à la vengeance. En effet, sitôt immolées - sitôt sanctifiées - voici qu'on invoque telle nation rassemblée et ne cédant pas aux amalgames. Il n'est d'ailleurs plus besoin de traquer les assassins puisque ceux-ci ont déjà rejoint leur au-delà. Quant aux fichés les plus radicaux susceptibles de frapper eux aussi, ils ne courent en réalité aucun risque: en effet, un peuple en pleine santé serait naturellement en droit d'exiger leurs têtes - mais nous ne le faisons pas, nous contentant de rendre hommage à nos pieuses et pitoyables victimes sans jamais demander réparation. Il faut donc en conclure que l'assassinat de masse relève d'une espèce de norme sacrée qui doit à la fois marquer profondément les esprits mais sans jamais provoquer l'escalade d'une violence démultipliée. D’ailleurs, désignées par le macabre tirage au sort du fameux mawvais endroit an mawvais moment, les victimes aléatoires entrent parfaitement dans la ronde de notre culte égalitariste. 


\section{« Nous sommes du côté de la vie »}

Mais nous n'avons de cesse de célébrer la mort. Le lien entre festivisme et culte mortifère n'est plus à établir. Depuis Philippe Muray, nous savons qu'Homo festivus et Homo funestus sont des frères jumeaux. En cela, le meurtre de masse révèle le sens profond de notre fin de civilisation funéraire. Il est le prétexte toujours recommencé d'une fête rituelle de la commémoration.

Une jouissance collective, inavouable et largement inconsciente, semble s'emparer du consommateur de médias au moment de l'annonce d'un attentat. Le Mal a frappé pour que la Fête puisse triompher à nouveau, avec davantage d'éclat. « Même pas peur ! même pas mal! » martèlent les pèlerins des places de nos villes meurtries, qu'un pétard d'enfant disperse comme une nuée d'oiseaux. Outre l'infantilisme, ces formules en disent long sur l'addiction mystique que les attentats suscitent. La stupéfaction des premières attaques a fait place à l'habituation sinistre puis à une dépendance médiatique quasi-religieuse. Une sorte de délectation se répand sur les réseaux sociaux. On compte les morts et les blessés avec frénésie. Le rite, aux relents archaïques, peut commencer. Les sacrificateurs ont des mines patibulaires et vénèrent un drapeau noir mais les officiants de la grande catharsis télévisée sont de jeunes journalistes impeccables, inondés de lumière. La communauté retrouve la communion qui lui faisait défaut. En cela, le terrorisme marque la victoire totale de l'Occident contemporain qui a fait du vivre-ensemble sa religion. Les attentats apparaissent comme les événements les plus sacrés de nos sociétés ennuyées et disloquées. Ils ne sont pas seulement «la musique d'ambiance de l'Europe» comme le dit Alain Finkielkraut. Ils sont en passe d'en devenir le plus haut cantique.

\section{Bibliographie}

Girard, René. «Entretien». Le Monde, 5 novembre 2011. Disponible sur :

http://www.lemonde.fr/archives/article/2001/11/05/rene-girard-philosophe-etanthropologue-ce-qui-se-joue-aujourd-hui-est-une-rivalite-mimetique-a-l-echelle-

planetaire_239636_1819218.html?xtmc=rene_girard_tincq\&xtcr=3 (Consulté le 25 août 2017).

" Que Valent nos Valeurs ?». La Croix (13 décembre 2002). http://www.lacroix.com/Archives/2002-12-13/Que-valent-nos-valeurs-Interview-Rene-Girard_NP_-2002-12-13-171969 (Consulté le 25 août 2017). Achever Clausewitz: Paris : Flammarion, 2011.

Murray, Philippe. Chers djihadistes... . Paris: editions Mille et Une Nuits, 2002. . Le Portatif. Paris: editions Mille et Une Nuits, 2006. Essais. Paris: Les Belles Lettres, 2015. 